Keywords: Melter, Sampling Error, Analytical Error

Retention Time: Permanent

\title{
Estimation of Total Error in DWPF's Reported Radionuclide Inventories (U)
}

February 27, 1995

\section{DISCLAIMER}

This report was prepared as an account of work sponsored by an agency of the United States Government. Neither the United States Government nor any agency thereof, nor any of their employees, makes any warranty, express or implied, or assumes any legal liability or responsibility for the accuracy, completeness, or usefulness of any information, apparatus, product, or process disclosed, or represents that its use would not infringe privately owned rights. Reference herein to any specific commercial product, process, or service by trade name, trademark, manufacturer, or otherwise does not necessarily constitute or imply its endorsement, recommendation, or favoring by the United States Government or any agency thereof. The views and opinions of authors expressed herein do not necessarily state or reflect those of the United States Government or any agency thereof.

\section{Westinghouse Savannah River Company}

P.O. Box 616

Aiken, SC 29802

Prepared by the U. S. Department of Energy under Contract DE-AC09-8\$SR18035 


\section{Disclaimer}

This report was prepared by Westinghouse Savannah River Company (WSRC) for the United States Department of Energy under Contract No. DE-AC09-8\%SR 18035 and is an account of work performed under that contract. Neither the United States Department of Energy, nor WSRC, nor any of their employees makes any warranty, expressed or implied, or assumes any legal liability or responsibility for the accuracy, completeness, or usefulness, of any information, apparatus, or product or process disclosed herein or represents that its use will not infringe privately owned rights. Reference herein to any specific commercial product, process, or service by trademark, name, manufacturer or otherwise does not necessarily constitute or imply endorsement, recommendation, or favoring of same by WSRC or by the United States Government or any agency thereof. The views and opinions of the authors expressed herein do not necessarily state or reflect those of the United States Government or any agency thereof. 


\section{DISCLAIMER}

Portions of this document may be illegible in electronic image products. Images are produced from the best available original document. 


\title{
WSRC-TR-95-0094
}

\section{Estimation of Total Error in DWPF's Reported Radionuclide Inventories (U)}

by

\author{
T. B. Edwards
}

Issued: February 27, 1995

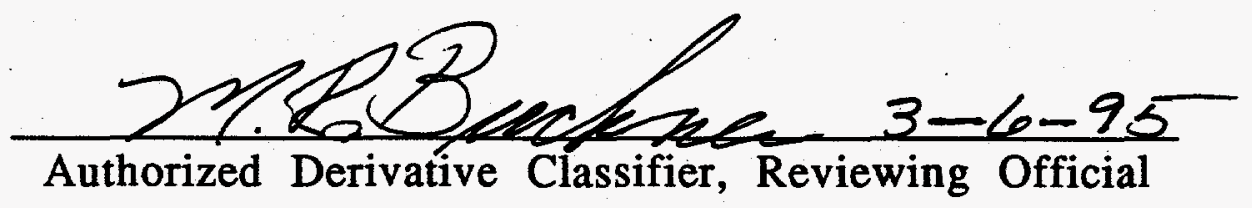

\section{SRTC}

Savannah River Technology Center, Aiken, SC 29802

Westinghouse Savannah River. Company

Prepared by the U. S. Department of Energy under Contract DE-AC09-88SR18035 
Document:

WI R CDT R-95-0094

Title: Estimation of Total Error in DWPF's Reported Radionuclide Inventories (U)

Approvals

$\frac{\text { Thomas B Sclevends }}{\text { T. B. Edwards, Author, ASET/ATS }}$

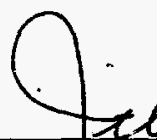

clement. Weber 2-28-95

J. H. Weber, Technical Reviewer, ASET/ATS

Date

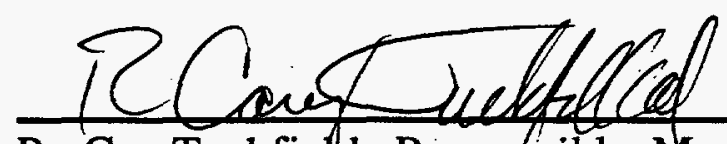

R. C. Tuckfiedd, Responsible Manager, ASET/ATS

Date 


\section{Table of Contents}

Section

1.0

2.0

3.0

4.0

Introduction

Page

Summary ...

1

Estimating Radionuclide Concentrations ............. 1

Concluding Comments . 


\subsection{INTRODUCTION}

This report investigates the impact of random errors due to measurement and sampling on the reported concentrations of radionuclides in DWPF's filled canister inventory resulting from each macro-batch. The objective of this investigation is to estimate the variance of the total error in reporting these radionuclide concentrations.

\subsection{SUMMARY}

Estimates of the total radionuclide concentrations for each DWPF macro-batch are to be determined by one of two methods. A propagation of variance for each of these two methods is completed to estimate the variance of the total error affecting these derived values. In this analysis, the errors considered reflect only random variation.

\subsection{ESTIMATING RADIONUCLIDE CONCENTRATIONS}

There are two methods for deriving estimates of the radionuclide concentrations for each batch of slury comprising a DWPF macro-batch: the direct and the indirect methods. Only one of these two methods is to be used for each of the radionuclides of interest.

\subsection{Radionuclide Concentrations Determined Via the Direct Method}

In the direct method, the contents of each MFT batch are measured, and the curies of radionuclide $r$ per gram of solids for this th batch, $c_{i}$, is determined. A measurement, $W_{i}$, of the weight per unit volume is also made as well as a measurement, $V_{i}$, of the volume transferred from the MFT to the melter for batch $\mathrm{i}$. The estimate of the total curies of radionuclide $r$ for the macro-batch (consisting of $b$ batches) is given by

$$
c_{r}=\sum_{i=1}^{b}\left(c_{i} w_{i} v_{i}\right)
$$

The errors associated with the $c_{i}, W_{i}$ and $V_{i}$ terms of equation (1) are assumed to be random errors. The standard deviations of these errors may be expressed in absolute units or, in the case of relative errors, as a percent of value. The analyses conducted below assumes that absolute units will be used. See Section 4.0 below for a discussion on how to handle relative standard deviations.

For each batch, the errors associated with the $c_{i}$ and $W_{i}$ terms are expected to be positively correlated, with $\operatorname{cov}\left(c_{i}, W_{i}\right)$ representing the covariance between the errors for these two terms. The errors associated with $V_{i}$ are assumed to be independent of the 
errors of the other two terms of equation (1). In addition, the errors associated with one MFT batch, $i$, are expected to be independent of all the other batches which make up the DWPF macro-batch. The independence of the errors across batches implies no systematic influence from tank volume calibrations or from instrument calibrations; that is, the instruments used to measure the $c_{i}$ and $W_{i}$ for batch $i$ are recalibrated before being used to measure $c_{j}$ and $W_{j}$ for batch $j$.

Using a Taylor's series expansion to estimate the variance of $C_{r}, \operatorname{var}\left(C_{r}\right)$, yields

$$
\begin{aligned}
\operatorname{var}\left(C_{r}\right) \approx \sum_{i=1}^{b}\left[\left(\frac{\partial C_{r}}{\partial C_{i}}\right)^{2} \operatorname{var}\left(C_{i}\right)+\left(\frac{\partial C_{r}}{\partial W_{i}}\right)^{2} \operatorname{var}\left(W_{i}\right)\right. & +\left(\frac{\partial C_{r}}{\partial V_{i}}\right)^{2} \operatorname{var}\left(V_{i}\right) \\
& \left.+2\left(\frac{\partial C_{r}}{\partial C_{i}}\right)\left(\frac{\partial C_{r}}{\partial W_{i}}\right) \operatorname{cov}\left(C_{i}, W_{i}\right)\right]
\end{aligned}
$$

where $\frac{\partial C_{r}}{\partial c_{i}}$ is the partial of $C_{r}$ with respect to $c_{i}$, and is equal to $W_{i} V_{i}$, and similarly,

$$
\frac{\partial C_{r}}{\partial W_{i}}=c_{i} V_{i} \quad \text { and } \quad \frac{\partial C_{r}}{\partial V_{i}}=c_{i} W_{i}
$$

This leads to the following estimate of the variance of $C_{r}$

$$
\begin{aligned}
\operatorname{var}\left(C_{r}\right) \approx \sum_{i=1}^{b}\left[W_{i}^{2} V_{i}^{2} \operatorname{var}\left(C_{i}\right)+c_{i}^{2} V_{i}^{2} \operatorname{var}\left(W_{i}\right)\right. & +c_{i}^{2} W_{i}^{2} \operatorname{var}\left(V_{i}\right) \\
& \left.+2 c_{i} W_{i} V_{i}^{2} \operatorname{cov}\left(c_{i}, W_{i}\right)\right]
\end{aligned}
$$

This direct approach assumes that all of the errors effecting these measurements (the $c_{i}$ 's, $W_{i}$ 's and $V_{i}$ 's) are random quantities (with correlations as described above). To complete the determination of the variance of $C_{r}$ in equation (3), the variances of $c_{i}, W_{i}$, and $V_{i}$ must be estimated from the uncertainties of these measurements. The uncertainties of $c_{i}$ and $W_{i}$, can be computed from the uncertainty of each of the corresponding procedures (sampling, which includes the tank inhomogeneity, and analytical, which includes sample preparation).

\subsection{Radionuclide Concentrations Determined Via the Indirect Method}

This method is deemed indirect since its estimates of the curie concentration (for the radionuclide of interest) per MFT batch depend on analytical results of SRS Tank Farm 
samples as opposed to samples taken directly from the DWPF MFT. The radionuclides which are to be estimated using this method must occur only in either the sludge or the PHA.

For each radionuclide, $r$ (determined with this indirect method), the estimate of the curie concentration for each MFT batch is given by

$$
C_{i, r}=\frac{1}{x} \sum_{a=1}^{x}\left(C_{\text {stream;ir } ; ~} f_{i ; a}\right)
$$

where $\mathrm{C}_{\text {stream;ir }}$ is the measured concentration of the radionuclide of interest in the stream (either sludge or PHA); that is, $C_{\text {stream;i; }}$ is the curies per gram of stream feeding into batch $\mathrm{i}$; and $\mathrm{f}_{\mathrm{i} ; \mathrm{a}}$ is a measure of the dilution factor for the stream (grams of solids in the MFT relative to grams of solids in the stream) relative to element a for a total of $x$ elements.

Each $f_{i ; a}$ is computed as the ratio of two measurement averages $\left(\bar{m}_{i ; a}\right.$ and $\left.\bar{s}_{a}\right)$. The errors associated with these two measurements are expected to be independent. The average $\bar{m}_{i ; a}$ is the estimate of the content of element $a$ in MFT batch $i$, and it is computed from a collection of $p_{i}$ analyses. The average $\bar{s}_{a}$ is the estimate of the content of element a in the input stream (e.g., sludge or PHA) to the MFT, and it is computed from a collection of $q$ analyses. These $q$ analyses of the input stream are conducted only once for a DWPF macro-batch, and these results are used in the determination of each of the $\mathrm{f}_{\mathrm{i} ; \mathrm{a}}$ values. The uncertainties of $\overline{\mathrm{m}}_{\mathrm{i}}$ a and $\bar{s}_{\mathrm{a}}$ can be readily computed from the uncertainty of each of the corresponding procedures (sampling \{includes tank uniformity\} and analytical) used in their respective derivation.

Specifically,

$$
\operatorname{var}\left(\bar{m}_{i ; a}\right)=\frac{\operatorname{var}\left(m_{i ; a}\right)}{p_{i}}
$$

and

$$
\operatorname{var}\left(\bar{s}_{\mathrm{a}}\right) \quad=\quad \frac{\operatorname{var}\left(s_{\mathrm{a}}\right)}{q}
$$

where $\operatorname{var}\left(m_{i} ; a\right)$ represents the variance of the random errors associated with a single $m_{i ; a}$ measurement and $\operatorname{var}\left(\mathrm{s}_{\mathrm{a}}\right)$ represents the same for a single $\mathrm{s}_{\mathrm{a}}$ measurement. The variances for these single measurements are to be estimated to allow equations (5) and (6) to be computed. Note that to ensure the reduction in variability suggested by equation (5), the $p_{\mathrm{i}}$ values of $\mathrm{m}_{\mathrm{i} ; \mathrm{a}}$ must share consistent sources of variation. A similar argument holds for the $q$ values of $s_{a}$. 
Using the indirect approach and the notation developed above, we get the following estimate for the total curies of radionuclide $r, C_{r}$, for a DWPF macro-batch:

$$
c_{r}=\sum_{i=1}^{b}\left[\frac{C_{\text {streamilir }}}{x} w_{i} v_{i} \sum_{a=1}^{x} \frac{\bar{m}_{i: a}}{\bar{s}_{a}}\right]
$$

where $W_{i}$ and $V_{i}$ are defined as in equation (1).

The variance of $C_{r}$ in equation (7) will be estimated using a Taylor's series expansion as in equation (2) above. However, some of the error terms affecting equation (7) may not be independent, and this possibility must be addressed appropriately in the estimation of the variance of $C_{r}$.

Specifically, the errors for the factors $\bar{m}_{i ; a}$ derived from samples from each MFT batch $i$ (the index a ranges over $x$ factors: $\mathrm{Fe}, \mathrm{Al}, \mathrm{Mn}$, and $\mathrm{Ca}$, for a given MFT batch) may be correlated. The errors for these measurements are assumed to be positively correlated; for example, if the estimate of the Fe tends to be high then the estimates of the other three elements will also tend to be high. Therefore, the Taylor's series expansion must involve the covariances for these factors. In addition, the errors of the $\bar{m}_{\mathrm{i} ; \mathrm{a}}$ may also be correlated with the errors of the measurement $W_{i}$, since all of these measurements are made on the same samples.

Similarly, the errors for the factors $\bar{s}_{a}$ derived from samples of the input stream (sludge or PHA) of the DWPF macro-batch may be correlated. The errors for these measurements for $\mathrm{Fe}, \mathrm{Al}, \mathrm{Mn}$, and $\mathrm{Ca}$ are assumed to be positively correlated; for example, if the estimate of the Fe tends to be high then the estimates of the other three elements will also tend to be high.

The errors for the other measurements of equation (7) are assumed to be independent since they are made on different samples and either by different labs or different techniques.

This leads to the following estimate of the variance of $C_{r}$ :

$$
\begin{aligned}
\operatorname{var}\left(C_{r}\right) \approx & \sum_{i=1}^{b}\left[\left(\frac{\partial C_{r}}{\partial C_{\text {stream;i; }}}\right)^{2} \operatorname{var}\left(C_{\text {stream;iri }}\right)+\left(\frac{\partial C_{r}}{\partial W_{i}}\right)^{2} \operatorname{var}\left(W_{i}\right)+\left(\frac{\partial C_{r}}{\partial V_{i}}\right)^{2} \operatorname{var}\left(V_{i}\right)\right. \\
& +\sum_{a=1}^{x}\left(\frac{\partial C_{r}}{\partial \bar{m}_{i ; a}}\right)^{2} \operatorname{var}\left(\bar{m}_{i ; a}\right)+\sum_{\substack{a=1 \\
a \neq c}}^{x} \sum_{\substack{c=1 \\
\partial \bar{m}_{i ; a}}}^{x}\left(\frac{\partial C_{r}}{\partial \bar{m}_{i ; c}}\right) \operatorname{cov}\left(\bar{m}_{i ; a}, \bar{m}_{i ; c}\right)
\end{aligned}
$$




$$
\begin{aligned}
& \left.+2 \sum_{a=1}^{x}\left(\frac{\partial C_{r}}{\partial \bar{m}_{i ; a}}\right)\left(\frac{\partial C_{r}}{\partial W_{i}}\right) \operatorname{cov}\left(\bar{m}_{i ; a}, W_{i}\right)\right]+\sum_{a=1}^{x}\left(\frac{\partial C_{r}}{\partial \bar{s}_{a}}\right)^{2} \operatorname{var}\left(\bar{s}_{a}\right) \\
& +\sum_{\substack{a=1 \\
a \neq c=1}}^{x} \sum_{\substack{c \\
\partial \bar{s}_{a}}}^{x}\left(\frac{\partial \mathrm{C}_{r}}{\partial \bar{s}_{c}}\right) \operatorname{cov}\left(\bar{s}_{a}, \bar{s}_{c}\right)
\end{aligned}
$$

where $\operatorname{cov}\left(\overline{\mathrm{m}}_{\mathrm{i} ; \mathrm{a}}, \overline{\mathrm{m}}_{\mathrm{i} ; \mathrm{c}}\right), \operatorname{cov}\left(\overline{\mathrm{m}}_{\mathrm{i} ; \mathrm{a}}, \mathrm{W}_{\mathrm{i}}\right)$, and $\operatorname{cov}\left(\bar{s}_{\mathrm{a}}, \overline{\mathrm{s}}_{\mathrm{c}}\right)$ represent the covariance between the errors for the two factors indicated,

and for each $\mathrm{i}$

$$
\begin{gathered}
\frac{\partial C_{r}}{\partial C_{\text {stream;irr }}}=W_{i} V_{i} \frac{1}{x} \sum_{a=1}^{x} \frac{\bar{m}_{i ; a}}{\bar{s}_{a}} ; \\
\frac{\partial C_{r}}{\partial W_{i}}=C_{\text {stream;ir }} V_{i} \frac{1}{x} \sum_{a=1}^{x} \frac{\bar{m}_{i ; a}}{\bar{s}_{a}} ; \\
\frac{\partial C_{r}}{\partial V_{i}}=C_{\text {stream;ir }} W_{i} \frac{1}{x} \sum_{a=1}^{x} \frac{\bar{m}_{i ; a}}{\bar{s}_{a}} ; \text { and }
\end{gathered}
$$

for each $i$ and $a$

$$
\frac{\partial C_{r}}{\partial \bar{m}_{i ; a}}=\frac{C_{\text {streamij:r }} W_{i} V_{i}}{x \bar{s}_{a}} ; \text { and }
$$

for each a

$$
\frac{\partial c_{r}}{\partial \bar{s}_{a}}=-\sum_{i=1}^{b} \frac{c_{\text {streamiir }} \bar{m}_{i ; a} W_{i} v_{i}}{x \bar{s}_{a}^{2}}
$$


Thus, the variance of $C_{r}$ given by equation ( 8 ) is estimated by

$$
\begin{aligned}
& \operatorname{var}\left(C_{r}\right) \approx \sum_{i=1}^{b}\left[\left(W_{i} v_{i} \frac{1}{x} \sum_{a=1}^{x} \frac{\bar{m}_{i: a}}{\bar{s}_{a}}\right)^{2} \operatorname{var}\left(C_{s t r e a m ; i r}\right)+\left(C_{\text {stream;irr }} V_{i} \frac{1}{x} \sum_{a=1}^{x} \frac{\bar{m}_{i a}}{\bar{s}_{a}}\right)^{2} \operatorname{var}\left(W_{i}\right)\right. \\
& +\left(C_{\text {stream;i;r }} W_{i} \frac{1}{x} \sum_{a=1}^{x} \frac{\bar{m}_{i: a}}{\bar{s}_{a}}\right)^{2} \operatorname{var}\left(V_{i}\right)+\sum_{\substack{a=1 \\
a \neq c=1}}^{x} \frac{\left(\frac{1}{x} C_{s t r e a m ; i ; r} W_{i} V_{i}\right)^{2}}{\bar{s}_{a} \bar{s}_{c}} \operatorname{cov}\left(\bar{m}_{i ; a}, \bar{m}_{i ; c}\right) \\
& +\sum_{a=1}^{x}\left(\frac{C_{\text {stream;ir: }} W_{i} V_{i}}{x \bar{s}_{a}}\right)^{2} \operatorname{var}\left(\bar{m}_{i ; a}\right) \\
& \left.+2 \sum_{a=1}^{x}\left(\frac{C_{\text {stream;irr }} V_{i}}{x}\right)^{2} \frac{W_{i}}{\bar{s}_{a}}\left(\sum_{c=1}^{x} \frac{\bar{m}_{i ; c}}{\bar{s}_{c}}\right) \operatorname{cov}\left(\bar{m}_{i ; a}, W_{i}\right)\right] \\
& +\sum_{a=1}^{x}\left(-\sum_{i=1}^{b} \frac{C_{\text {stream:iir }} \bar{m}_{i ; a} W_{i} V_{i}}{x \bar{s}_{a}^{2}}\right)^{2} \operatorname{var}\left(\bar{s}_{a}\right)
\end{aligned}
$$

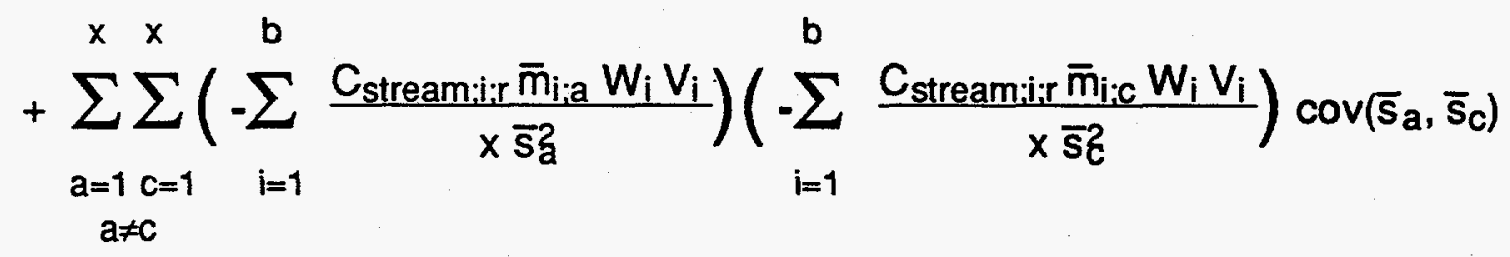

This indirect approach assumes that all of the errors effecting these measurements (except for those discussed above) are independent, random quantities. To complete the determination of the variance of $C_{r}$ in equation (9), the variances of the $C_{\text {stream;ir, }}$ $W_{i}, \bar{m}_{i ; a}, \bar{s}_{a}$, and $V_{i}$ must be estimated from the uncertainties of these measurements. The covariances of the correlated errors must also be estimated.

A note regarding estimates of the covariances of the $\bar{m}_{\mathrm{i} ; \mathrm{a}}$ and $\overline{\mathrm{s}}_{\mathrm{a}}$. These covariances may be difficult to estimate. If the errors affecting these factors are positively correlated, 
WSRC-TR-95-0094

February 27, 1995

Page 7 of 7

then a bounding (conservative) estimate of the covariance between any two of these factors is the product of their standard deviations. These estimates may be used in equation (7) to provide the estimate of the variance of $C_{r}$.

4.0 CONCLUDING COMMENTS

As more definitive estimates of the errors affecting these measurements are identified, they may be used in these calculations to provide a representative estimate of the total error in the reported radionuclide inventory for each DWPF macro-batch. Specifically, if some of the errors are relative errors, then estimates of the corresponding variances should be entered appropriately into equations (3) or (9). For example, if y is a measurement with a relative standard deviation of $n \%$, then the estimate of the variance of the error associate with the measurement $y$ is equal to $\left(\frac{y n}{100}\right)^{2}$.

The approach presented in this memo assumes that the reported radionuclide . concentrations and other measurements will be corrected for known biases associated with vessel uniformity, sampling, and analysis. If not accounted for or if steps are not taken (such as recalibrating instrumentation between MFT batches), the systematic errors from these sources could be significant contributors to the overall uncertainty. In this analysis, the errors considered reflect only random variation. 